mgr inz. Mirostaw Lastowski

inz. Mieczysław Oporowski

Instytut Pojazdów Szynowych „Tabor”

\title{
Potencjalne możliwości odzysku energii podczas hamowania elektrodynamicznego e.z.t. eksploatowanych w Polsce
}

$W$ artykule przedstawiono wyniki badań ruchowych elektrycznych zespołów trakcyjnych (e.z.t.) wyprodukowanych w ostatnich latach i eksploatowanych w Polsce. Badania zostaty wykonane przez Laboratorium Badawcze Instytutu Pojazdów Szynowych „Tabor” w Poznaniu. Na podstawie uzyskanych przebiegów wykazano potencjalne możliwości odzysku energii podczas hamowania elektrodynamicznego.

\section{Wstęp}

Tematyka odzyskiwania energii hamowania pojazdu trakcyjnego „odżywa” często w okresach trudnych dla gospodarek na całym świecie. W ostatnich latach dodatkowym bodźcem są zauważalne zmiany klimatyczne związane z emisją gazów cieplarnianych i wzrost cen surowców służących do wytwarzania energii. Przekłada się to na rozwiązania konstrukcyjne nowo budowanych oraz modernizowanych pojazdów trakcyjnych, a zwłaszcza e.z.t., tramwajów i trolejbusów, w których $\mathrm{z}$ racji częstych zatrzymywań efekty ekonomiczne związane ze zwrotem energii podczas hamowania są wymierne.

\section{Elektryczny autobus szynowy 308B}

Badania wykonano w sierpniu i wrześniu 2005 roku na trasie Poznań Wschód - Września - Poznań Wschód. Przedmiotem badań był dwuczłonowy elektryczny autobus szynowy typu 308B o oznaczeniu kolejowym EN81-001, przeznaczony do eksploatacji na normalnych zelektryfikowanych liniach kolejowych. Producentem autobusu jest spółka Pojazdy Szynowe PESA Bydgoszcz S.A. Holding.

Widok ogólny badanego autobusu szynowego pokazano na fot. 1 .

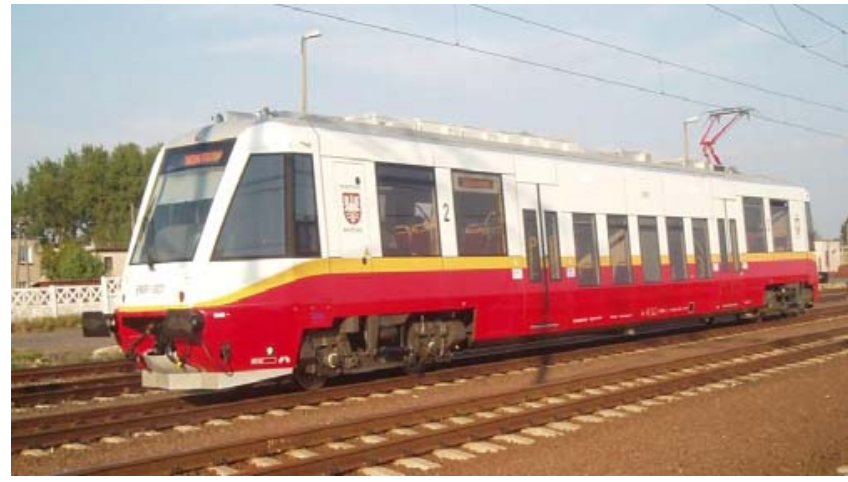

Fot. 1. Ogólny widok autobusu szynowego 308B (EN81-001)
Podstawowe dane techniczne:

- układ osi

Bo' +2 '

(dwie osie napędowe i dwie toczne)

- prędkość maksymalna $\quad 120 \mathrm{~km} / \mathrm{h}$

- przyspieszenie rozruchu $0,6 \div 0,8 \mathrm{~m} / \mathrm{s}^{2}$

- moc całkowita pojazdu $\quad 560 \mathrm{~kW}$

- napięcie sieci trakcyjne $3000 \mathrm{VDC}$

- masa w stanie służbowym $\quad 54 \mathrm{Mg}$

- liczba miejsc siedzących 60

- liczba pasażerów ogółem 80

Wyniki badań przedstawiono na rys. 1 i 2 :

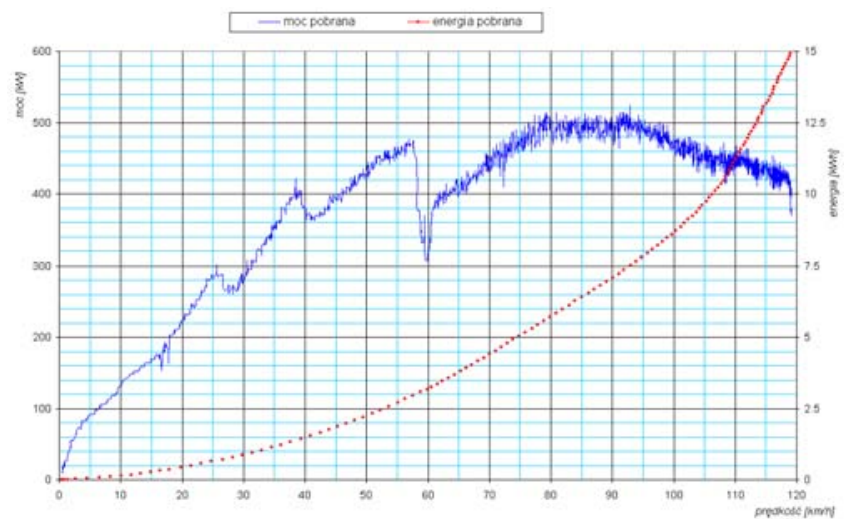

Rys. 1. Moc i energia autobusu 308B w czasie rozruchu (obciążenie pełne; czas rozruchu $134 \mathrm{~s}$ )

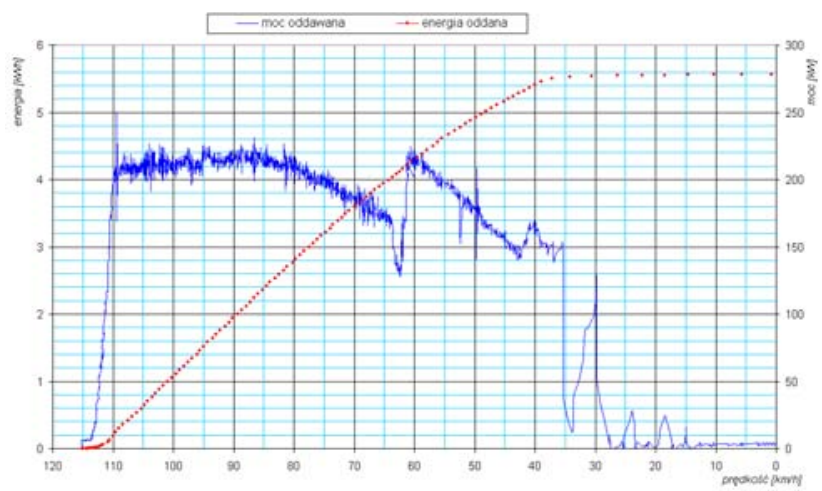

Rys. 2. Moc i energia oddawana do sieci w czasie hamowania elektrodynamicznego autobusu 308B (obciążenie pełne; czas hamowania $120 \mathrm{~s}$ ) 


\section{Elektryczny zespól trakcyjny $16 \mathrm{WE}$}

Badania wykonano w kwietniu i maju 2006 roku na Torze Doświadczalnym Żmigród-Węglewo oraz na trasie Poznań Wschód - Konin - Poznań Wschód. Przedmiotem badań był czteroczłonowy elektryczny zespół trakcyjny typu 16WE o oznaczeniu kolejowym ED74-01, nr fabr. 001, przeznaczony do eksploatacji na normalnych zelektryfikowanych liniach kolejowych. Producentem e.z.t. jest spółka Pojazdy Szynowe PESA Bydgoszcz S.A. Holding.

Widok ogólny badanego zespołu trakcyjnego pokazano na fot. 2.

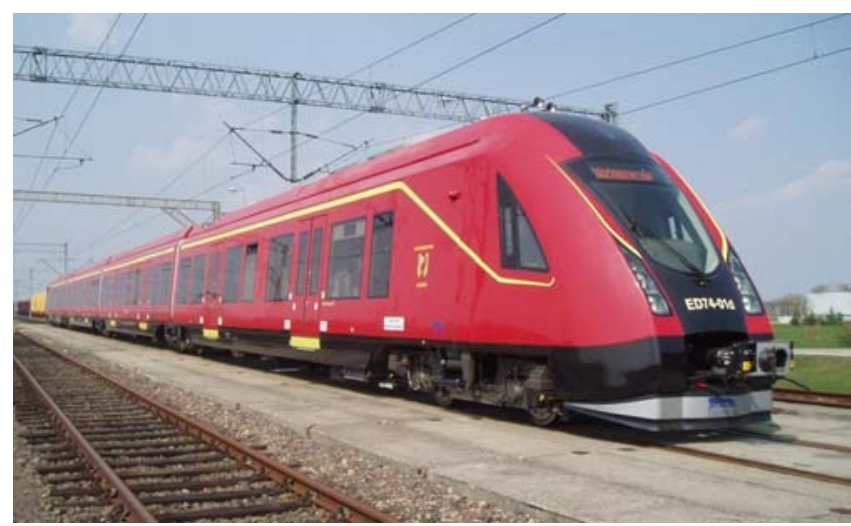

Fot. 2. Ogólny widok elektrycznego zespołu trakcyjnego 16WE (ED74-01)

Podstawowe dane techniczne:

- układ osi $\mathrm{Bo}^{\prime}+2{ }^{\prime}+2{ }^{\prime}+2{ }^{\prime}+\mathrm{Bo}^{\prime}$

(dwa wózki napędne i trzy toczne)

- prędkość maksymalna

$160 \mathrm{~km} / \mathrm{h}$

- przyspieszenie rozruchu

- moc całkowita pojazdu

$0,6 \div 0,8 \mathrm{~m} / \mathrm{s}^{2}$

- napięcie sieci trakcyjne

$2000 \mathrm{~kW}$

- masa w stanie służbowym

$3000 \mathrm{VDC}$

- liczba miejsc siedzących

$154 \mathrm{Mg}$

225

- liczba pasażerów ogółem

450

Wyniki badań przedstawiono na rys. 3 i 4:

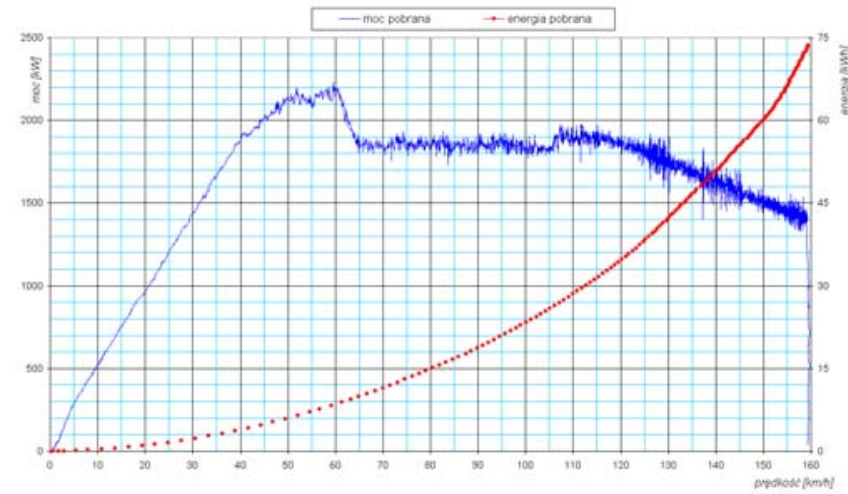

Rys. 3. Moc i energia e.z.t. 16WE w czasie rozruchu (obciążenie pełne; czas rozruchu $165,5 \mathrm{~s}$ )

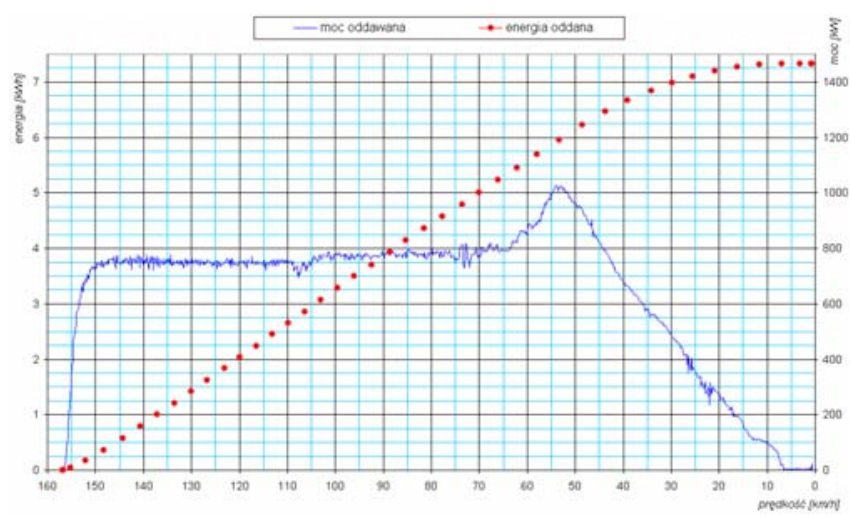

Rys. 4. Moc i energia oddawana do sieci w czasie hamowania elektrodynamicznego e.z.t. 16WE (obciążenie pełne; czas hamowania $46 \mathrm{~s}$ )

\section{Elektryczny zespół trakcyjny Flirt}

Badania wykonano w marcu i kwietniu 2008 roku na trasie Poznań Wschód - Zbąszynek. Przedmiotem badań był elektryczny zespół trakcyjny Flirt Polska o oznaczeniu kolejowym ER75-001, przeznaczony do eksploatacji na normalnych zelektryfikowanych liniach kolejowych. Producentem e.z.t. jest spółka Stadler Bussnang AG ze Szwajcarii.

Widok ogólny badanego zespołu trakcyjnego pokazano na fot. 3 .

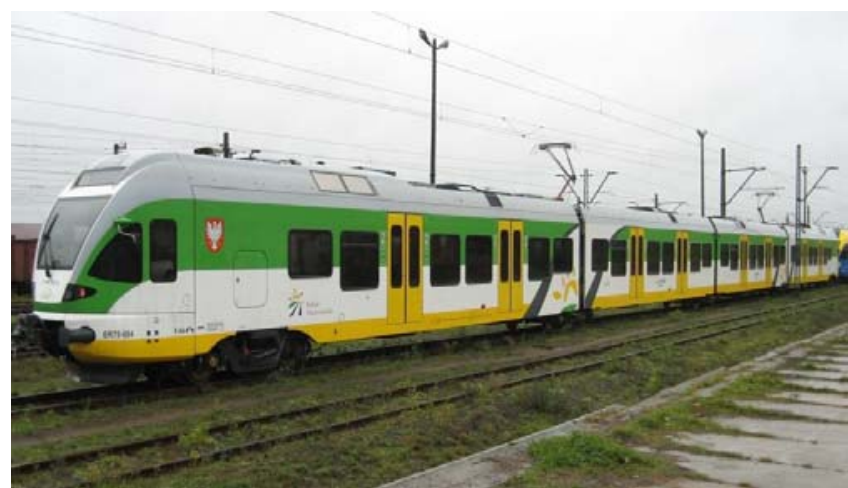

Fot. 3. Ogólny widok zespołu trakcyjnego Flirt Polska

Podstawowe dane techniczne:

- układ osi

Bo' $+2{ }^{\prime}+2{ }^{\prime}+2^{\prime}+\mathrm{Bo}^{\prime}$

(dwa wózki napędne i trzy toczne)

- prędkość maksymalna

$160 \mathrm{~km} / \mathrm{h}$

- przyspieszenie max

$1.01 \mathrm{~m} / \mathrm{s}^{2}$

- moc całkowita pojazdu: maksymalna ciagła

$2200 \mathrm{~kW}$

$1600 \mathrm{~kW}$

- napięcie sieci trakcyjne

- masa w stanie służbowym

- liczba miejsc siedzących

3000 VDC

$154 \mathrm{Mg}$

183

- liczba pasażerów ogółem

496

Wyniki badań przedstawiono na rys. 5 i 6 : 


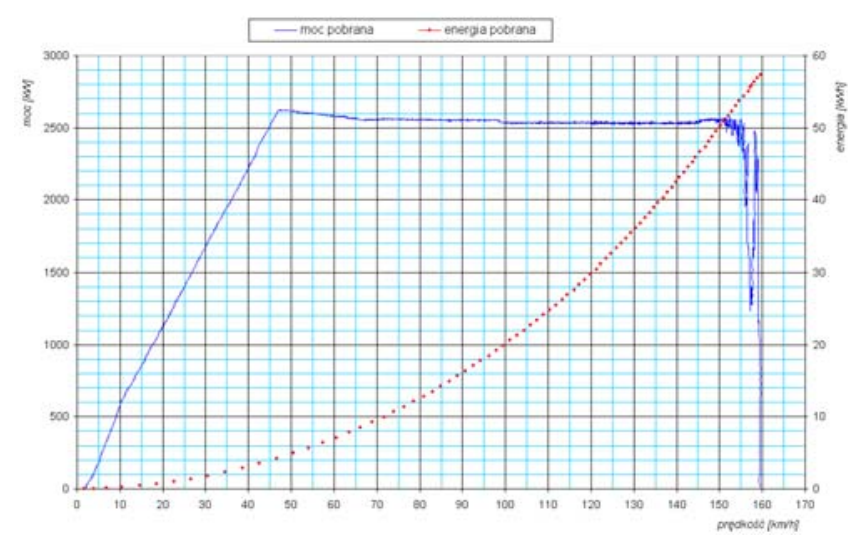

Rys. 5. Moc i energia e.z.t. Flirt w czasie rozruchu (obciążenie pełne; czas rozruchu $90 \mathrm{~s}$ )

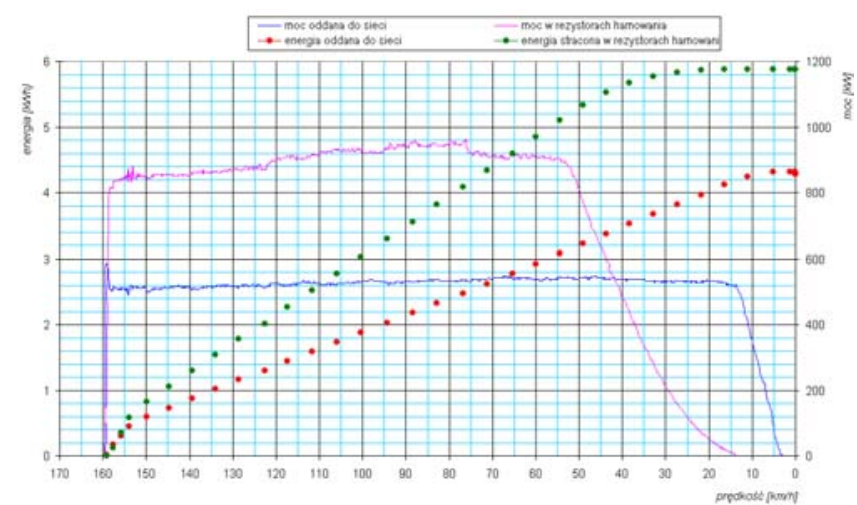

Rys. 6. Moc i energia ezt Flirt podczas hamowania elektrodynamicznego (obciążenie służbowe, czas hamowania $33 \mathrm{~s}$ )

\section{Podsumowanie i wnioski}

Na rys. 7 przedstawiono zestawienie porównawcze energii pobranej podczas rozruchu i oddanej do sieci trakcyjnej podczas hamowania elektrodynamicznego dla badanych pojazdów. Stosunek energii odzyskanej do pobranej wynosi od blisko $10 \%$ do prawie $40 \%$.
Otrzymane wyniki ukazują w naoczny sposób, że warto ponieść nakłady na uzyskanie możliwości zwrotu energii podczas hamowania pojazdów. Jest to szczególnie istotne dla pojazdów uczestniczących w ruchu miejskim i aglomeracyjnym o małych odległościach międzyprzystankowych, a więc dużej ilości hamowań. Flota tych pojazdów jest duża, co dodatkowo może zwiększyć oszczędności.

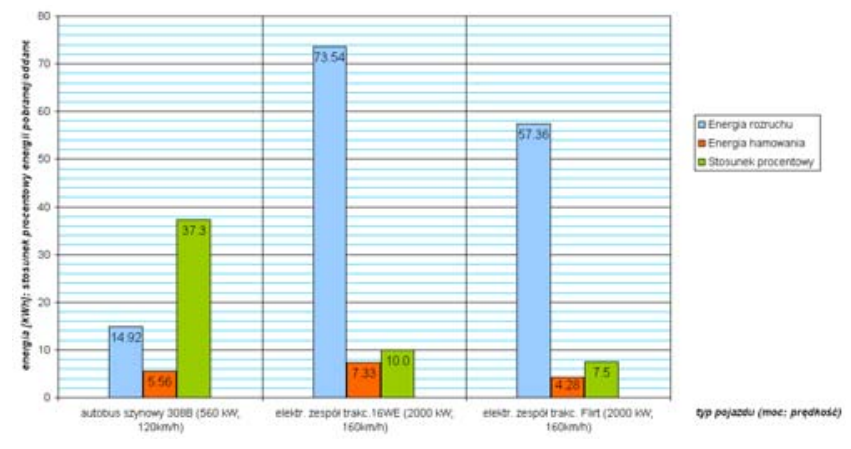

Rys. 7. Zestawienie porównawcze energii pobranej podczas rozruchu i oddanej przy hamowaniu elektrodynamicznym dla omawianych pojazdów trakcyjnych

\section{Literatura}

[1] RP-0277 Badania właściwości trakcyjnych elektrycznego autobusu szynowego typu 308B. IPS „Tabor”, Poznań, 10.10.2005.

[2] RP-0326 Badania właściwości trakcyjnych elektrycznego zespołu trakcyjnego typu 16WE. IPS „,Tabor”, Poznań, 12.06.2006.

[3] RP-0432 Badania hamulca elektrycznego zespotu trakcyjnego Flirt Polska. IPS „Tabor”, Poznań, 12.04.2008. 